Revista Brasileira de Farmacognosia Brazilian Journal of Pharmacognosy 22(2): 412-417, Mar./Apr. 2012

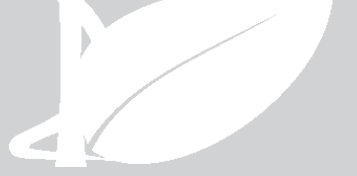

Article

Received 1 Apr 2011

Accepted 19 Jul 2011

Available online 14 Oct 2011

Keywords:

biochemical parameters

extracts

hepatotoxicity

Oxalis corniculata

thioacetamide

ISSN 0102-695X

http://dx.doi.org/10.1590/S0102-

$695 \times 2011005000189$

\section{Evaluation of hepatoprotective activity of aqueous and ethanolic extract of Oxalis corniculata against intoxication of thioacetamide induced rats}

\author{
Kuntal Das, ${ }^{* 1}$ Anil Kumar Kathiriya, ${ }^{2}$ Kumar E. P., ${ }^{3}$ Benson M. \\ K., ${ }^{2}$ John Wilking Einstein ${ }^{2}$ \\ ${ }^{1}$ Department of Pharmacognosy and Phytochemistry, St. John's Pharmacy College, \\ India, \\ ${ }^{2}$ Department of Pharmacology and Toxicology, St. John's Pharmacy College, \\ India, \\ ${ }^{3}$ Department of Pharmacology and Toxicology, Karpagaram University, India.
}

\begin{abstract}
The present study was carried out to evaluate the hepatoprotective activity of aqueous and ethanolic leaves extracts of Oxalis corniculata L., Oxalidaceae, against thioacetamide-induced hepatotoxicity. Hepatotoxicity was induced in Wistar rats of either sex by subcutaneous injection of thioacetamide. An aqueous and ethanolic extract of aerial parts of $O$. corniculata (200 and $400 \mathrm{mg} / \mathrm{kg} / \mathrm{day}$ ) were evaluated. Oral administration of $O$. corniculata aqueous and ethanolic leaves extract at $400 \mathrm{mg} / \mathrm{kg}$ resulted in a significant reduction in SGOT $(146.42 \pm 2.54$ and $136.75 \pm 1.37$ IU/L respectively), SGPT $(81.96 \pm 3.15$ and $72.05 \pm 2.33 \mathrm{IU} / \mathrm{L}$ respectively), GGTP $(16.6 \pm 0.49$ and $15.02 \pm 0.68 \mathrm{IU} / \mathrm{L}$ respectively), ALP (241.86 \pm 3.94 and $202.42 \pm 5.37 \mathrm{IU} / \mathrm{L}$ respectively) and total bilirubin $(0.226 \pm 0.00 \mathrm{mg} / \mathrm{dL} 0.288 \pm 0.01 \mathrm{mg} / \mathrm{dL}$ respectively $)$ content that were lesser than positive control, thioacetamide damaged rats. Histology of the liver sections of the animals treated with the extract also showed dose dependent reduction of necrosis. Hence the study concluded that $O$. corniculata has potential hepatoprotective activity.
\end{abstract}

\section{Introduction}

Oxalis corniculata L., Oxalidaceae, a subtropical plant being native of India, are commonly known as creeping woodsorrel. It is a delicate-appearing, low growing, herbaceous plant and abundantly distributed in damp shady places, roadsides, plantations, lawns, nearly all regions throughout the warmer parts of India, especially in the Himalayas up to $8,000 \mathrm{ft}$ - cosmopolitan (Kirtikar \& Basu, 1975). Traditionally the plant is well known with its varsatile medicinal uses likely treatment for relieve the intoxication produced by Datura, as a refrigerant (Mohammad \& Mir, 2000), decoction of roots is useful for worms, giddiness, diarrhea and dysentery (Kirtikar \& Basu, 1975). The leaves are useful for cough, cold, fever and as antihelmintic. The leaves are useful for stomach ache, stop bleeding from wounds and as antihelmintic (Mohammad \& Mir, 2000). Recently its anticancer activity was established which produced amazing out come from the study (Kathiriya et al., 2010). Phytochemical investigations of $O$. corniculata have revealed the presence of tannins, palmitic acid, a mixture of oleic, linoleic, linolenic and stearic acids (Raghvendra et al., 2006). Methanolic and ethanolic extracts of this plant show the presence of carbohydrate, glycosides, phytosterols, phenolic compounds, flavanoids, proteins $(12.5 \%)$, amino acids and volatile oil. It also showed the presence of calcium, fiber and tannin. Leaves contain tartaric acid and citric acids, calcium oxalate, flavones etc (Unni et al., 2009). In spite of several uses, there are some more beneficial activities are revealed recently which it show the further demand of this plant in worldwide especially in India. Hence the present study has investigated with respect to beneficial uses and highlighted the contribution of $O$. corniculata in modern system of herbal medicine as a new hepatoprotective drug.

\section{Material and Methods}

\section{Collection of plant materials and extraction}

Healthy, disease free plant of Oxalis corniculata L., Oxalidaceae, collected from Tirupati 
was authenticated by Dr. Madhava Chetty, Department of Botany, Sri Venkateshwara University, Tirupati, Andhra Pradesh, India. The coarse powder $(500 \mathrm{~g})$ of $O$. corniculata was exhaustively extracted using $2.5 \mathrm{~L}$ of ethanol in a Soxhlet extractor for a period of $48 \mathrm{~h}$. Both the extracts were concentrated under reduced pressure using rota vacuum evaporator at a bath temperature below $60{ }^{\circ} \mathrm{C}$. The yield of AEOC and EEOC extracts were 11.6 and $9 \%(\mathrm{w} / \mathrm{w})$ respectively.

\section{Experimental animals}

Healthy Wistar rats of either sex, weighing 150-250 g, bred in the animal house of St. John's Pharmacy College were used in the study. The animals were maintained at standard housing conditions and fed standard pellet diet and water ad libitum. All procedures were performed according to the Institutional Animal Ethics Committee's approval.

\section{TAA-induced hepatotoxicity}

Hepatotoxicity was induced by the subcutaneous administration of TAA, at a dose of $100 \mathrm{mg} / \mathrm{kg}$ body weight, as a $2 \%(\mathrm{w} / \mathrm{v})$ solution in distilled water. Six rats were used per group in the study. TAA was administered on the sixth day of the 7-day study period to all of the groups of animals except Group I, which served as control and received the vehicle of the extracts. Group II served as TAA control and received vehicle of the extracts. Group III-VII received the following treatments from $1^{\text {st }}$ to $7^{\text {th }}$ day of the study: III: AEOC extract at $200 \mathrm{mg} / \mathrm{kg} /$ day dose; IV:AEOC extract at $400 \mathrm{mg} / \mathrm{kg} /$ day dose; V: EEOC extract at $200 \mathrm{mg} / \mathrm{kg} /$ day dose; VI: EEOC extract at $400 \mathrm{mg} / \mathrm{kg} /$ day dose; VII: Silymarin at $50 \mathrm{mg} / \mathrm{kg} /$ day dose.

\section{Assessment of liver function}

\section{Biochemical estimations}

Twenty-four hours after administration of the last dose of the drugs, the animals were anaesthetized with anaesthetic ether for withdrawing the blood samples by cardiac puncture after an over-night fast. The blood was allowed to coagulate at room temperature for $45 \mathrm{~min}$ and then centrifuged at $2500 \mathrm{rpm}$ for $15 \mathrm{~min}$ for separation of serum. The serum was used for the biochemical analysis, which includes SGOT, SGPT, alkaline phosphatase, GGTP and total bilirubin by using biochemical estimation kits. The livers of all of the animals were taken out, washed with cold saline and blotted dry between filter papers. The livers were weighed and 10\% homogenate of liver were prepared in ice cold $0.15 \mathrm{M}$ potassium chloride solution using glass teflon tissue homogenizer. Amount of protein $/ \mathrm{mg}$ of tissue was also determined (Lowry et al., 1951).

\section{Histopathological studies}

Liver from each of the six animals in all of the groups were removed after dissection and preserved in $10 \%$ buffered formol saline ( $\mathrm{pH} 7.4$ ). Then representative blocks of liver tissues from each lobe were taken and possessed for paraffin embedding using the standard microtechnique (Galighor \& Kozloff, 1976). Sections $(5 \mu \mathrm{m})$ of livers stained with hemotoxylin and eosin, were observed microscopically for observing the liver damage.

\section{Statistical analysis}

Results of biochemical estimations are expressed as mean $\pm \mathrm{SD}$. The variations in a set of data have been estimated by performing Bonferroni's test of multiple comparisons. Minimum level of significance was fixed at 0.05 .

\section{Results}

The administration of TAA resulted in a marked increase in serum SGOT, SGPT, GGT, ALP and total bilirubin. The protective actions of AEOC and EEOC on hepatotoxicity induced by TAA are summarized in Table 1 and 2. Maximum hepatoprotective activity was

Table 1. Effect of AEOC and EEOC on serum SGOT, SGPT, ALP, GGTP and total bilirubin.

\begin{tabular}{lccccc}
\hline \multicolumn{1}{c}{ Group } & SGOT (IU/L) & SGPT (IU/L) & ALP (IU/L) & GGTP (IU/L) & Total bilirubin (IU/L) \\
\hline Control & $101.41 \pm 1.62$ & $34.38 \pm 1.55$ & $111.8 \pm 2.52$ & $7.2 \pm 0.31$ & $0.174 \pm 0.01$ \\
TAA treated & $174.36 \pm 1.26^{* *}$ & $109.06 \pm 0.80^{* *}$ & $304.68 \pm 3.92^{* *}$ & $22.25 \pm 0.52 * *$ & $0.579 \pm 0.03^{* *}$ \\
AEOC $200 \mathrm{mg} / \mathrm{kg}+\mathrm{TAA}$ & $163.52 \pm 2.97 * *$ & $101.18 \pm 1.50^{* *}$ & $269.44 \pm 3.52^{* *}$ & $19.57 \pm 0.60$ & $0.404 \pm 0.01$ \\
AEOC $400 \mathrm{mg} / \mathrm{kg}+\mathrm{TAA}$ & $146.42 \pm 2.54^{* *}$ & $81.96 \pm 3.15^{* *}$ & $241.86 \pm 3.94 * *$ & $16.6 \pm 0.49^{* *}$ & $0.318 \pm 0.01^{* *}$ \\
EEOC $200 \mathrm{mg} / \mathrm{kg}+\mathrm{TAA}$ & $152.38 \pm 2.03^{* *}$ & $87.56 \pm 2.03^{* *}$ & $252.9 \pm 3.79^{* *}$ & $18.72 \pm 0.40$ & $0.341 \pm 0.01$ \\
EEOC 400 mg/kg+TAA & $136.75 \pm 1.372^{* *}$ & $72.05 \pm 2.33^{* *}$ & $202.42 \pm 5.37 * *$ & $15.02 \pm 0.68^{* *}$ & $0.288 \pm 0.01 * *$ \\
Silymarin 50 mg/kg+TAA & $118.08 \pm 1.39^{* *}$ & $53.55 \pm 1.78^{* *}$ & $160.14 \pm 4.09^{* *}$ & $9.9 \pm 0.67^{* *}$ & $0.193 \pm 0.00^{* *}$ \\
\hline
\end{tabular}

Mean \pm SD; $\mathrm{n}=6$ rats in each group; $* *$ Significant at $p<0.05$. 
observed at $400 \mathrm{mg} / \mathrm{kg}$ dose level of EEOC, which was comparable to that of silymarin. EEOC was found to be more potent than the AEOC.

Table 2. Effect of AEOC and EEOC on liver glutathione and MDA levels.

\begin{tabular}{lcc}
\hline \multicolumn{1}{c}{ Group } & $\begin{array}{c}\text { Liver glutathione } \\
\left(\times 10^{-3} \mathrm{~mol} / \mathrm{mg}\right. \\
\text { protein })\end{array}$ & $\begin{array}{c}\text { MDA } \\
\text { (nmol/g liver wt. })\end{array}$ \\
\hline Control & $1.48 \pm 0.07$ & $16.01 \pm 0.06$ \\
TAA treated & $1.54 \pm 0.05^{* *}$ & $37.14 \pm 0.08$ \\
AEOC $200 \mathrm{mg} / \mathrm{kg}+\mathrm{TAA}$ & $2.06 \pm 0.06^{* *}$ & $32.08 \pm 1.02 * *$ \\
AEOC $400 \mathrm{mg} / \mathrm{kg}+\mathrm{TAA}$ & $2.78 \pm 0.08^{* *}$ & $29.93 \pm 1.12^{* *}$ \\
EEOC $200 \mathrm{mg} / \mathrm{kg}+\mathrm{TAA}$ & $1.83 \pm 0.08^{* *}$ & $33.07 \pm 1.14$ \\
EEOC $400 \mathrm{mg} / \mathrm{kg}+\mathrm{TAA}$ & $2.35 \pm 0.05^{* *}$ & $30.02 \pm 1.21^{* *}$ \\
Silymarin $50 \mathrm{mg} / \mathrm{kg}+\mathrm{TAA}$ & $3.08 \pm 0.17^{* *}$ & $13.64 \pm 0.98^{* *}$ \\
\hline Mean $\pm \mathrm{SD} ; \mathrm{n}=6 \mathrm{rats}$ in each group;**Significant at $p<0.05$.
\end{tabular}

The histological observations of the control animals showed normal hepatocytes with well preserved cytoplasm, prominent nucleus, nucleolus and central vein. There was no sign of inflammation, fatty change or necrosis in these animals (Figure 1). In animals

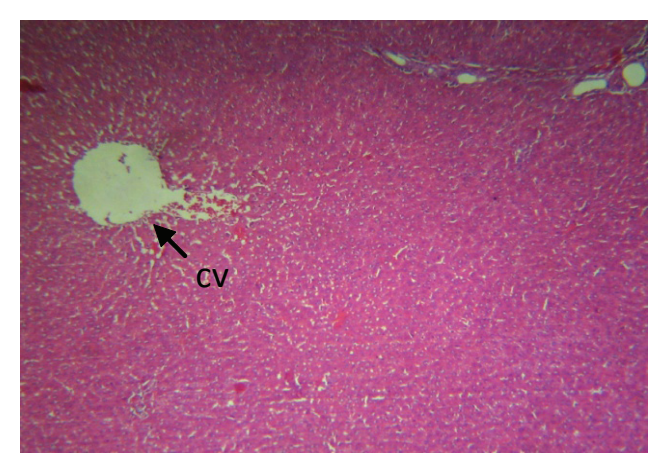

Figure 1. Photomicrograph of liver from control animals showed normal architecture of liver.

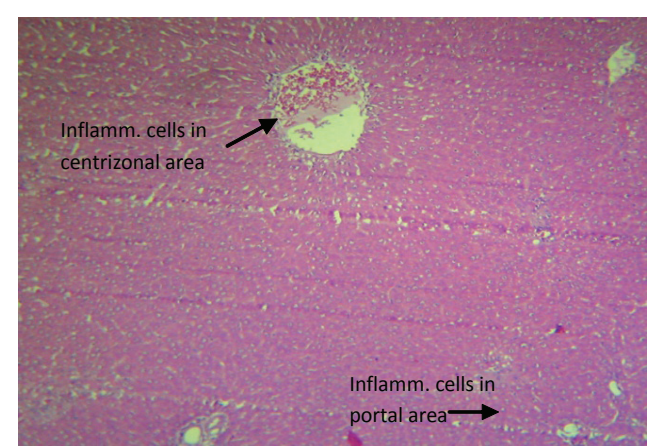

Figure 3. Photomicrograph of liver from animal treated with $200 \mathrm{mg} / \mathrm{kg}$ of AEOC and TAA showing a inflammation in the periportal and centrizonal area. treated with TAA only, liver sections showed periportal lymphoplasmacytic infiltration, centrizonal inflammation and necrosis. Inflammatory cells were observed in the portal triad. Cytoplasmic vacuoles and ballooning degeneration of hepatocytes were also observed (Figure 2). Pretreatment with AEOC at $200 \mathrm{mg} / \mathrm{kg}$ dose showed periportal and centrizonal inflammation and disappearance of centrizonal necrosis. Focal centrizonal hepatocytes also showed cytoplasmic vacuoles and balloon degeneration (Figure 3). AEOC at $400 \mathrm{mg} / \mathrm{kg}$ dose showed greater reduction in periportal and centrizonal inflammation and no any centrizonal necrosis. Focal areas also showed degenerative changes of periportal hepatocytes (Figure 4). EEOC at $200 \mathrm{mg} / \mathrm{kg}$ showed periportal lymphoplasmacytic infiltration and congested central vein surrounded by lymphocytes. No centrizonal necrosis was identified (Figure 5). EEOC at $400 \mathrm{mg} /$ $\mathrm{kg}$ showed few portal traid with periportal lymphocytic infiltration, central vein and rest of the hepatic parenchyma appeared unremarkable. No centrizonal necrosis was identified (Figure 6). Pretreatment with silymarin at 50 $\mathrm{mg} / \mathrm{kg}$ dose showed almost normal liver lobule with no sign of necrosis in the centrizonal area and portal triad. Only focal periportal inflammation was observed (Figure 7).

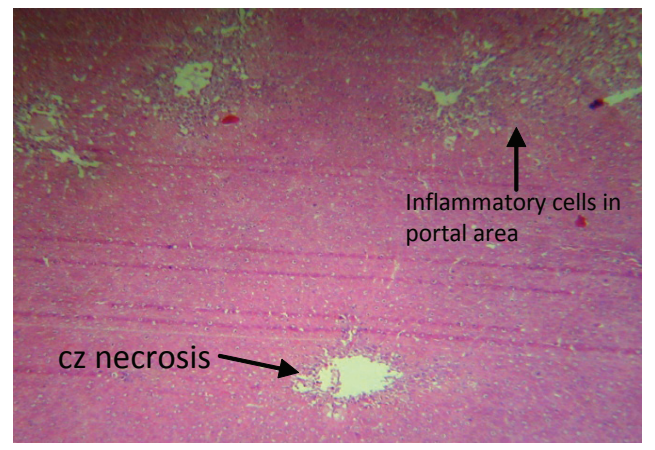

Figure 2. Photomicrograph of liver from animal treated with TAA only showing inflammatory cells in centrilobular area and also around the portal triad. The inflammatory infiltrate is seen spreading into the liver lobule

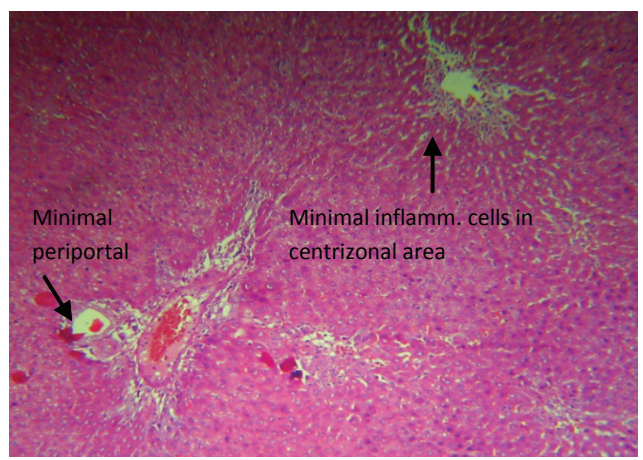

Figure 4. Photomicrograph of liver from animal treated with 400 $\mathrm{mg} / \mathrm{kg}$ of AEOC and TAA showing a minimal inflammation in the periportal and centrizonal area. 


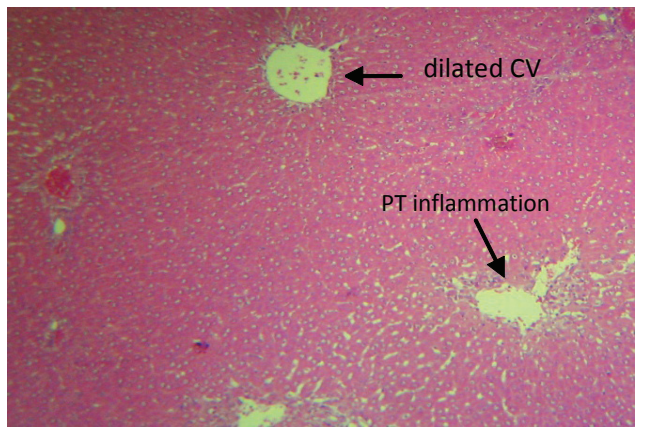

Figure 5. Photomicrograph of liver from animal treated with $200 \mathrm{mg} / \mathrm{kg}$ of EEOC and TAA showing dilated central vein and inflammatory cells infiltration around portal traid.

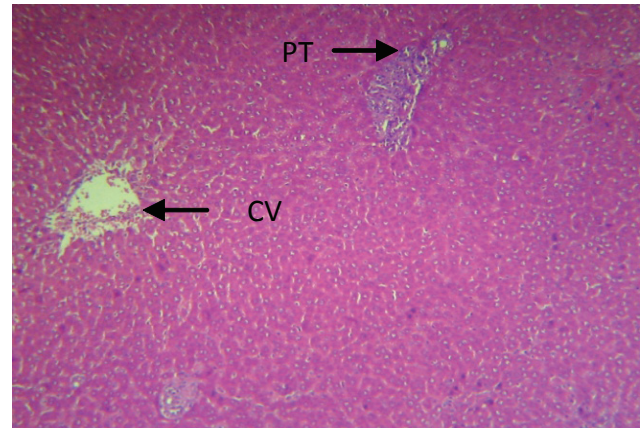

Figure 6. Photomicrograph of liver from animal treated with $400 \mathrm{mg} / \mathrm{kg}$ of EEOC and TAA showing a focal periportal inflammation

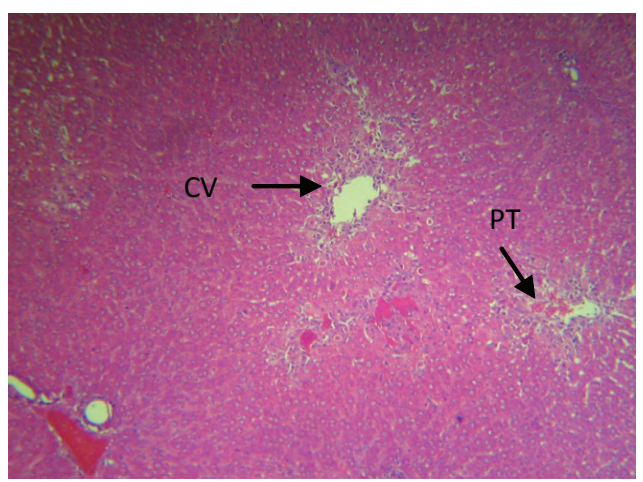

Figure 7. Photomicrograph of liver from animal treated with $50 \mathrm{mg} / \mathrm{kg}$ of silymarin and TAA showing a focal periportal inflammation.

\section{Discussion}

The present study indicates the potential mild hepatoprotective activity of Oxalis corniculata L. It is also found to possess free radical scavenging activity in TAA induced hepatotoxicity in wistar rats. There is no detailed published report on the hepatoprotective activity of Oxalis corniculata L., so an initial dose of $400 \mathrm{mg} / \mathrm{kg}$ of the aqueous and ethanolic extract of Oxalis corniculata L. was chosen considering the high yield of the extract.

TAA has been used as a tool to induce hepatotoxicity in experimental animals to produce various grade of liver damage including nodular cirrhosis, liver cell proliferation, production of pseudolobules, and parenchymal cell necrosis (Mitra et al., 1998). Several investigators have reported that a single dose of this hepatotoxin can produce centrilobular hepatic necrosis and chronic administration leads to cirrhosis in rats (Zimmerman, 1978). Mechanism of thioacetamide toxicity is due to the formation of thioacetamide-5-oxide which is responsible for the change in cell permeability, increased intracellular concentration of $\mathrm{Ca}^{++}$, increase in nuclear volume and enlargement of nucleoli and also inhibits mitochondrial activity which leads to cell death
(Ambrose et al., 1950; Neal \& Halpert, 1982). Several researchers have suggested that part of hepatocellular injury induced by TAA is mediated through oxidative stress caused by the action of cytokines through lipid peroxidation (So et al., 2002; Okuyama et al., 2004). Reduced hepatic antioxidant function has also been suggested as one of the mechanism of TAA induced hepatotoxicity (Wang et al., 1999). In a number of animal models, thioacetamide induced cirrhosis seem to resemble the important features of human diseases (Torres et al., 1996). Elevated levels of serum enzymes are indicative of cellular leakage and loss of functional integrity of cell membrane in liver (Drotman \& Lawhorn, 1978). Damage to liver cells cause leakage of cellular enzymes into serum. In the present study, TAA was found to cause significant elevations in the levels of serum AST, ALT, GGT, ALP and total bilirubin. Pretreatment with AEOC and EEOC were found to significantly reverse these toxin induced changes. Hence a reduction in the levels of these enzymes demonstrates membrane stabilizing activity of both of the extracts. Flavanoids present in Oxalis corniculata could be responsible for the membrane stabilizing activity.

Lipid peroxidation is a common event in toxic phenomenon. It occurs to a limited extent under 
normal physiological conditions, but external factors can augment this process so that it escapes cell control which leads to damage of macromolecules such as lipids in the cell membrane and eventually causing membrane damage and death of cell. Glutathione is an important endogenous antioxidant system that is found in particularly high concentration in liver and it is known to have key functions in protective processes. Both the extracts resulted in significant increase in the liver glutathione levels as compared to TAA group and at higher doses (i.e., at 200 and $400 \mathrm{mg} / \mathrm{kg}$ AEOC and 200 and $400 \mathrm{mg} / \mathrm{kg}$ EEOC) the increase was statistically significant as compared to control group. Treatment with both of the extracts also resulted in significant decrease in the lipid peroxidation in the liver as shown by decrease in the MDA levels in the liver. Hence, both of the drugs resulted in inhibition of lipid peroxidation which could be due to enhanced hepatic glutathione content as a result of drug treatment. These results suggest that the hepatoprotective action of Oxalis corniculata might be due to the presence of antioxidants like flavonoids, vitamin C and $\alpha$ carotenes (Davila et al., 1989). Centrizonal necrosis, which involves the cells around the central hepatic vein, occurs in viral hepatitis, TAA, carbon tetrachloride and chloroform toxicity, and anoxic states such as cardiac failure and shock (Chandrasoma \& Taylor, 1998). In the present experiment, it indicates the damage caused by TAA to the hepatocytes. The decrease in the necrosed area demonstrated by both of the extracts as well as decrease in the infiltration of the inflammatory cells in the liver lobules is indicative of therapeutic efficacy of the plant extracts. Silymarin is a standardized seed extract of Silybum marianum, which contains flavonolignans. Silymarin at doses up to $100 \mathrm{mg} /$ $\mathrm{kg}$ has been used as a standard hepatoprotective agent by numerous investigators. Dose of $50 \mathrm{mg} / \mathrm{kg}$ of silymarin was selected in the present investigation based on some published studies demonstrating the hepatoprotective activity of this dose (Boigk et al., 1997; Bhadauria et al., 2007). In the present study, silymarin was used as the standard to compare the activity of both of the extracts. Our study showed the hepatoprotective potential of both the extract of Oxalis corniculata and silymarin pretreatment against thioacetamide induced hepatotoxicity is due to multiple mechanisms.

\section{Conclusion}

It can be concluded that both the extracts of Oxalis corniculata, have potential hepatoprotective activity and attenuates the hepatotoxic effects of TAA but among them ethanolic extract of Oxalis corniculata showed high significant results than former extract by membrane stabilizing effect and acting as an antioxidant.

\section{Acknowledgements}

The authors are grateful to Dr. Thejasvi, for providing his expertise in carrying out histopathological studies.

\section{References}

Ambrose AM, DeEds F, Rather LJ 1950. Further studies on toxicity of thioacetamide in rats. Proc Soc Exp Biol Med 74: 134-140.

Bhadauria M, Nirala SK, Shukla S 2007. Propolis protects CYP 2E1 enzymatic activity and oxidative stress induced by carbon tetrachloride. Mol Cell Biochem 302: 215-224.

Boigk G, Stroedter L, Herbst H, Waldschmidt J, Riecken EO, Schuppan D 1997. Silymarin retards collagen accumulation in early and advanced biliary fibrosis secondary to complete bile duct obliteration in rats. Hepatology 26: 643-649.

Chandrasoma P, Taylor CR 1998. Concise pathology. Stamford: Appleton \& Lange, p. 450

Dávila R, Zumárraga M, Andía I, Friedhoff AJ 1989. Persistence of cyclicity of the plasma dopamine metabolite, homovanillic acid, in neuroleptic treated schizophrenic patients. Life Sci 44: 1117-1121.

Drotman RB, Lawhorn GT 1978. Serum enzymes are indicators of chemical induced liver damage. Drug Chem Toxicol 1: 163-171.

Galighor AE, Kozloff EN 1976. Essentials of practical micro technique. 2 Ed. New York: Lea and Febiger.

Kathiriya A, Das K, Kumar EP, Mathai KB 2010. Evaluation of antitumor and antioxidant activity of Oxalis Corniculata Linn. against ehrlich ascites carcinoma on mice. Iran $J$ Cancer Prev 3: 157-165.

Kirtikar, Basu 1975. Indian medicinal plants. Vol 1. 3 Ed. New Delhi: MS periodical experts, p. 437.

Lowry OH, Rosebrough NJ, Farr AL, Randall RJ 1951. Protein measurement with the Folin phenol reagent. J Bio Chem 193: 265-275.

Mitra SK, Venkataranganna MV, Sundaram R, Gopumadhavan S 1998. Protective effect of HD-03, a herbal formulation, against various hepatotoxic agents in rats. J Ethnopharmacol 63: 181-186.

Mohammad IS, Mir AK 2000. Folk use of medicinal herbs of Margalla Hills National Park, Islamabad. $J$ Ethnopharmacol 69: 48-56.

Neal R A, Halpert J 1982. Toxicology of thiono-sulfur compounds. Annu Rec Pharmacol Toxicol 22: 321-339.

Okuyama H, Shimahara Y, Nakamura H, Araya S, Kawada N, Yamaoka Y, Yodoi J 2004. Thioredoxin prevents thioacetamide-induced acute hepatitis. Comparative Hepatology 3: S6.

Raghvendra MP, Satish S, Raveesha KA 2006. Phytochemical analysis and antibacterial activity of Oxalis Corniculata, a known medicinal plant. My SCIENCE 1: 72-78. 
Evaluation of hepatoprotective activity of aqueous and ethanolic extract of Oxalis corniculata against intoxication of thioacetamide induced rats

So EC, Wong KL, Huang TC, Tasi SC, Liu CF 2002. Tetramethylpyrazine protects mice against thioacetamide-induced acute hepatotoxicity. $J$ Iomed Sci 9: 410-414.

Torres MI, Fernandez I, Fontana L, Gil A, Rios A 1996. Influence of dietary nucleotide on liver structural recovery and hepatocyte binucleral recovery and hepatocyte binuclearity in cirrhosis induced by thioacetamide. Gut 38: 260-264.

Unni BG, Archana B, Wann SB, Singh HR, Barabruni D, Minakshi B 2009. Phytochemical and antibacterial study of traditional medicinal plants of north east India on Escherichia coli. Asian Journal of Experimental Science 23: 103-108.
Wang H, Peng R, Kong R, Li Y 1999. Serum glutathione S-transferase activity as an early marker of thioacetamide-induced acute hepatotoxicity in mice. Wei Sheng Yan Jiu 28: 179-180.

Zimmerman HJ 1978. Hepatotoxicity. New York: Appleton Century Crofts, p. 122.

\section{*Correspondence}

Kuntal Das

Department of Pharmacognosy and Phytochemistry, St. John's Pharmacy College

Vijayanagar, B'lore-104, India

Tel.: +919632542846 